\title{
Enhancing students' language in collective processes of knowledge construction in group work: the case of enlarging figures
}

\author{
Kirstin Erath ${ }^{1}$ D \\ Accepted: 10 March 2021 / Published online: 29 March 2021 \\ (c) The Author(s) 2021
}

\begin{abstract}
Against the background of providing learning opportunities for meaningful mathematics for all students, the presented Design Research study had the goal of investigating how to support students facing language barriers while learning mathematics in phases of unmoderated group work. For this purpose, learning meaningful mathematics and demanding discourse practices are connected with quality interaction characteristics identified in research on productive group work. This theoretical consideration was implemented in a learning arrangement on similarity by means of four design principles for enhancing language in group work on meaningful mathematics. The empirical insights show to what extent the intended demanding discourse practices and quality interaction characteristics can be identified in different steps of knowledge construction, and to what extent they are supported by the design element 'role cards'. Instead of calling for less unmoderated group work for students facing language barriers, the results of the study suggest that more research is needed to design scaffolds matching students' needs, aside from whole-class discussions.
\end{abstract}

Keywords Demanding discourse practices · Quality interaction characteristics · Group work · Design Research · Similarity

\section{Introduction}

Active participation in teacher-led whole-class discussions has been shown to be important for students' learning of meaningful mathematics (Walshaw \& Anthony 2008). During these discussions, students engage in reporting on procedures, explaining meanings of concepts and operations, arguing about the validity of a claim, and describing patterns in a general way (Prediger et al. 2019). However, explaining meanings, arguing, and describing patterns in a general way are shown to be more difficult for students than, for instance, reporting on procedures (Erath et al. 2018) from a linguistic perspective. Thus, these discourse practices are summarized as 'demanding discourse practices' (abbreviated DDP).

Many qualitative studies have shown that talking about meaningful mathematics in more advanced steps of knowledge construction is often connected to engaging in DDPs (Barwell, 2020; Erath et al. 2018; King, 2008; Mercer et al.

Kirstin Erath

kirstin.erath@math.tu-dortmund.de

1 Institute for Development and Research in Mathematics Education (IEEM), TU Dortmund University, Dortmund, Germany
1999; Moschkovich, 2015). At the same time, participating in DDPs is challenging for all students, and in particular for students with low academic language proficiency (Erath et al. 2018; Prediger et al. 2019). However, students can succeed if they are adaptively supported by the teacher. Yet most whole-class discussions are carried by only a few students and support is only rarely provided for the others (Erath et al. 2018).

One way to provide more students with learning opportunities through active participation in discussions on meaningful mathematics is through enhancing students' language in group work, since more students have the opportunity to speak simultaneously in different groups. As I outline in this paper, participating in these discussions is linguistically challenging. Given the usual diversity of language backgrounds in typical mainstream classrooms (Barwell et al. 2016), the identification of academic language proficiency as a key factor for disadvantage in mathematics learning (Prediger et al. 2018), and the aim of providing conceptual learning opportunities for all students, in the study presented here I focus on developing support for mono- and multilingual students facing language barriers while learning mathematics. Hence the question is to what extent designed-in scaffolds and the other students in the group can support 
students in overcoming possible language barriers and engaging in quality interaction.

The Design Research study MAGENTA had the goal of contributing to answering this question by investigating students' speech in groups working with a purposefully designed learning arrangement. From a mathematical perspective, the focus was on the question of the extent to which mathematical processes connected to a meaningful learning of similarity in German grade 9 classrooms are supported. From a language perspective, the focus was on the question of the extent to which characteristics of productive wholeclass discussions (e.g., accomplishing demanding discourse practices, valuing contributions from different students, connecting different ideas) can also be facilitated and supported in students' group talk. The overarching aim was to develop a language-responsive learning arrangement for the topic similarity. That aim entailed a composition of tasks (with accompanying teacher manual) that simultaneously provide mathematics and academic language learning opportunities, and thus treat language as an explicit learning goal in mathematics classrooms. This aim implied a need for further disentangling the language demands in group work, in order to design learning arrangements in such a way that they provide learning opportunities to all students. To achieve this aim, the presented study followed the research approach of topic-specific specification of language demands (Prediger $\&$ Zindel, 2017) for the case of language demands on the discourse level and the topic similarity.

As is outlined in Sect. 2, research on language-responsive teaching and learning mathematics, and research on productive group work in general, has not yet addressed or designed learning arrangements specifically for students facing language barriers working in groups. Thus, in the presented study I built on design principles that proved productive for supporting students facing language barriers in learning mathematics. However, as the empirical part of this paper shows, the first step is presented here while there is still a need for further design research on how to adapt these design principles and the related ideas for scaffolds.

As this paper focuses on the language perspective of the larger project, a literature review on discourse practices and learning meaningful mathematics (Sect. 2.1) and supporting quality interaction in group work (Sect. 2.2) are presented, followed by the conceptual framework of the study (Sect. 2.3). Section 3 presents the research context and, after describing methodology and methods (Sect. 4), empirical insights are exemplified by three extracts from two groups (Sect. 5). Section 6 gives a brief summary, discussion, and outlook.

\section{Theoretical background}

Section 2.1 provides an overview on research from a participationist perspective in mathematics education with a focus on language learning. Section 2.2 refers to literature from mathematics education but also broader approaches applied to several subjects that focus on conditions for productive group work. On this basis, the conceptual framework for pursuing the larger research question in view is presented in Sect. 2.3.

\subsection{Discourse practices and learning meaningful mathematics}

The term participationist perspective (Krummheuer, 2011; Sfard, 2008) subsumes theoretical approaches that conceptualize learning as participation in classroom discourses. Often following the tradition of Vygotsky (1978), learning mathematics is conceptualized as "a process of enculturation into mathematical practices, including discursive practices (e.g., ways of explaining, proving, or defining mathematical concepts)" (Barwell, 2014, p. 332). Learning is seen as tightly linked to participation in classroom interaction that is mainly based on verbal communication. In this context, meaningful mathematics is often conceptualized as being opposed to a reduction of mathematics to computing and manipulating symbols, and thus meaningful learning of mathematics foregrounds conceptual understanding and problem solving (e.g., Moschkovich, 2015). The following studies match this perspective but further elaborate on the language that is involved in classroom discourse on meaningful mathematics.

Discourse is used and defined in diverse ways in mathematics education depending on the wider context and aims of the study and the linguistic point of reference. For instance, Gee's definition of Discourse is often used to highlight social and political perspectives in the mathematics classroom (Moschkovich, 2015; Setati, 2005). For further investigating Setati's (2005) observation of different Discourses related to learning procedural or conceptual mathematics, it is useful to refer to a linguistic approach that facilitates further differentiation of kinds of discourses that are relatable to different steps in knowledge construction. Prediger et al. (2019) identified four discourse practices as most important in mathematics classrooms, as follows:

- Reporting on procedures.

- Explaining the meaning of concepts and operations.

- Arguing about the validity of a claim.

- Describing patterns in a general way. (p. 444) 
The authors based their work on the definition of oral discourse practices as interactively co-constructed and contextualized multi-turn units from Interactional Discourse Analysis, which is compatible with participationist perspectives (Erath et al. 2018). The conceptualization of discourse practices as a repeated communicative pattern for solving different communicative problems then allows us to relate different discourse practices with different steps of knowledge construction: Explaining serves to convey and construct knowledge and is particularly necessary in phases of developing and consolidating knowledge with their focus on communicating new insights; arguing about the validity of a claim is integral in mathematics education as it serves to solve the communicative problem of opposing arguments; describing serves to communicate about the perception of objects or patterns that might not be open to the other students; and reporting serves to retrospectively articulate actions and processes, and thus, for instance, serves the purpose of talking about how one solved a task.

Hence, the four discourse practices are all important for learning mathematics. However, in particular, explaining meanings of mathematical concepts and operations is pointed out as key for meaning-making processes (Barwell, 2020; Moschkovich, 2015). From a participationist perspective, providing opportunities for participating in these discourse practices is crucial for all students but particularly for students facing language barriers (Moschkovich, 2015).

Researchers in mathematics education have already developed and investigated several approaches for enhancing students' language and supporting them in meaning-making processes (Erath et al. 2021). However, many studies refer to whole-class discussions or teacher-led group work and point to the crucial role of teachers' support in interaction: it is the teachers' responsibility to encourage all students to participate also in advanced steps of knowledge construction and to adaptively support those students facing language barriers, without withdrawing the mathematical responsibility from them. Thus, the question remains how these students can be supported in participating in group work in order to provide access to the related mathematics learning opportunities.

\subsection{Supporting quality interaction in group work}

Learning opportunities arising from students' collaborative work in groups for learning cognitively demanding knowledge in general (Cohen, 1994; King, 2008), and meaningful mathematics in particular (Mercer \& Sams, 2006), have been repeatedly highlighted. However, even 30 years ago, researchers started to identify the conditions under which group work can be productive (Cohen, 1994; Webb, 1991). In addition to the appropriateness of the task and the composition of the group, several studies point to quality interaction as a necessary condition. The latter is a focus of the presented study and is further elaborated in the literature review by outlining related characteristics and approaches from research with the aim of supporting students in this endeavor.

Quality interaction is defined differently in research projects on promoting group work, depending on the theoretical background and larger aims of the researchers. Widely acknowledged are Johnson and Johnson's (2008) work on collaboration and their definition of "promotive interaction", the Complex Instruction approach with its focus on heterogeneous classrooms and equity (Cohen \& Lotan, 1997; Lotan, 2008), and "exploratory talk" (Barnes \& Todd, 1977) as elaborated in the Thinking Together Project and researched in mathematics classrooms (Mercer \& Sams, 2006; Mercer et al. 1999). Each research team showed qualitatively, and in large quantitative studies, connections between quality interaction and learning gains. As examples, Johnson and Johnson's, as well as Mercer and colleagues', definitions and lists of characteristics for quality interaction are shown in Fig. 1. The summary shows that, for group work to be productive, the interaction should be marked by participants helping each other, sharing information, resources and knowledge, constructively challenging each other's thinking, and jointly making decisions.

Beyond identifying conditions for productive group work, research teams designed and investigated support for students. Assigning roles to students (Cohen, 1994; Cohen \& Lotan, 1997; Johnson \& Johnson, 2008; Webb, 1991), establishing norms for working in groups (Cohen \& Lotan, 1997; Mercer et al. 1999), and explicit teaching of strategies and behavior related to acting according to the characteristics of quality interaction (Cohen, 1994; Lotan, 2008; Mercer et al. 1999; Webb, 1991), are repeatedly shown as promoting learning.

The Complex Instruction approach, as well as Johnson and Johnson's approach, show the effectiveness of establishing norms related to social skills combined with assigning roles for supporting quality interaction and thus learning. Assigning roles supports quality interaction as the responsibility for the learning process is explicitly handed over to students, and positive interdependence is created (Cohen, 1994; Cohen \& Lotan, 1997; Johnson \& Johnson, 2008; Webb, 1991). For example, the roles of facilitator and recorder/reporter have been shown empirically to be supportive of quality interaction and learning (Cohen \& Lotan, 1997). Figure 2 shows the roles from Complex Instruction as implemented in mathematics education by the youcubed project team (youcubed 2020, n.d.).

Establishing norms for collaboration is also a focus of the Thinking Together Project: exploratory talk is shown as improving students' language and reasoning skills as well as individual learning and understanding of mathematics 


\section{Quality interaction}

Promotive interaction may be defined as individuals encouraging and facilitating each other's efforts to complete tasks, achieve, or produce in order to reach the group's goal. It consists of a number of variables, including mutual help and assistance, exchange of needed resources, effective communication, mutual influence, trust, and constructive management of conflict.

(Johnson \& Johnson 2008, p. 12f)

Student actions in promotive interaction:

1. Providing each other with efficient and effective help and assistance [...]

2. Exchanging needed resources such as information and materials and processing information more efficiently and effectively [...]

3. Providing each other with feedback in order to improve the subsequent performance of their assigned tasks and responsibilities [...]

4. Challenging each other's conclusions and reasoning in order to promote higher quality decision making and greater insight into the problems being considered [...]

5. Advocating the exertion of efforts to achieve mutual goals $[\ldots]$

6. Influencing each other's efforts to achieve the group's goals $[\ldots]$

7. Acting in trusting and trustworthy ways [...]

8. Being motivated to strive for mutual benefit [...]

9. Having a moderate level of arousal characterized by low anxiety and stress $[\ldots]$

10. Taking the perspective of others $[\ldots]$ and thus able to explore different point of view [...]

(Johnson \& Johnson 2008, p. 24)
Exploratory talk is that in which partners engage critically but constructively with each other's ideas. Statements and suggestions are sought and offered for joint consideration. These may be challenged and counterchallenged, but challenges are justified and alternative hypotheses are offered. In exploratory talk, knowledge is made publicly accountable and reasoning is visible in the talk. (Mercer et al. 1999, p. 97)

Ground rules for exploratory talk:

1. all relevant information is shared;

2. the group seeks to reach agreement;

3. the group takes responsibility for decisions;

4. reasons are expected;

5. challenges are accepted;

6. alternatives are discussed before a decision is taken; and

7. all in the group are encouraged to speak by other group members.

(Mercer et al. 1999, p. 98f.)

Fig. 1 Two sets of definitions for, and characteristics of, quality interaction

(Mercer \& Sams, 2006; Mercer et al. 1999). For enabling students to engage in exploratory talk, an explicit, practical introduction provided by the teacher proved successful (Mercer \& Sams, 2006), including establishing a set of ground rules.

The studies presented in Sect. 2.2 highlight the importance of quality interaction. For mainstream classrooms and in heterogeneous settings, establishing norms and assigning roles combined with explicit teaching of strategies and skills have proven effective in supporting students working in groups. In addition, Lotan (2008) reports that students with diverse language proficiency all showed significant learning gains in content knowledge and academic English language from teaching according to the Complex Instruction approach in a social science classroom. This result further supports the goal in the presented study of designing a language-responsive learning arrangement based on a task involving meaningful mathematics that makes working in a group necessary.

\subsection{Conceptual framework of the presented study}

The presented project is rooted in a participationist perspective (Sect. 2.1), intertwined with Interactional Discourse Analysis following Erath et al. (2018). For the purpose of pursuing the research question, the interplay of learning 
Fig. 2 Roles assigned to students working in groups in the youcubed project (youcubed 2020, n.d.)
Facilitator: Make sure your group reads all the way through this card together before you begin. "Who wants to read? Does every one get what to do?"Keep your group together. Make sure everyone's ideas are heard. "Did anyone see it a different way? Are we ready to move on?" Be sure everyone can explain.

Recorder/Reporter: Your group needs to organize all your results. Your results need to show everyone's ideas, be well-organized, and use color, arrows, and other math tools to communicate your mathematics, reasons, and connections. "How do we want to show that idea?" Be ready to join the teacher for a huddle.

\begin{tabular}{|ll|}
\hline Resource Manager: & $\begin{array}{l}\text { Get materials for your team. } \\
\text { Make sure all questions are team questions. } \\
\text { When your team is done, call the teacher over to debrief the } \\
\text { mathematics. }\end{array}$ \\
\hline Team Captain: & $\begin{array}{l}\text { Remind your team to find reasons for each mathematical } \\
\text { statement, and search for connections among the different } \\
\text { statements. "How do you know that for sure? How does that } \\
\text { relate to..." } \\
\text { No talking outside your group! }\end{array}$ \\
\hline
\end{tabular}

meaningful mathematics and classroom discourse needs to be further disentangled with a focus on phases of group work (see Fig. 3). Since the focus is on student-student interaction, teachers' productive teaching practices (Erath et al. 2021) are not further investigated, even though they are the focus of many studies on enhancing language in classroom discourse. Instead, the DDPs explaining meanings, arguing, and describing patterns in a general way are carved out in their role for talking about meaningful mathematics. In addition, quality interaction characteristics identified in research on productive group work are related to DDPs to form a base for designing scaffolds and analyzing students' collective knowledge construction processes.

Following a participationist perspective (see Sect. 2.1), learning mathematics is seen as inseparable from students' participation in classroom discourse, including students' speaking and interaction in group work. For the purpose of the presented study, it is useful to follow the definition of oral discourse practices as derived in Sect. 2.1, and further refine it to make the different demands in various steps of knowledge construction even more explicit.

The discourse practices defined by Interactional Discourse Analysis have already been related to mathematics learning (Erath et al. 2018), and Prediger et al. (2019) identified reporting on procedures, explaining meanings, arguing about the validity of a claim, and describing patterns in a general way as most important in mathematics classrooms. However, discourse practices differ in their linguistic demand: in general, reporting or describing visual impressions is less demanding than explaining or arguing since the latter necessitate causal, conditional, or adversative conjunctions whereas reporting and, to some extent, describing visual impressions are connected to temporally sequencing content elements (Erath et al. 2018). Furthermore, the interdisciplinary team theoretically and empirically elucidated an alignment of talking about conceptual knowledge in advanced steps of knowledge construction and explaining meanings, arguing, or describing general 
Fig. 3 Overview of the interplay of learning meaningful mathematics and different aspects of classroom discourse

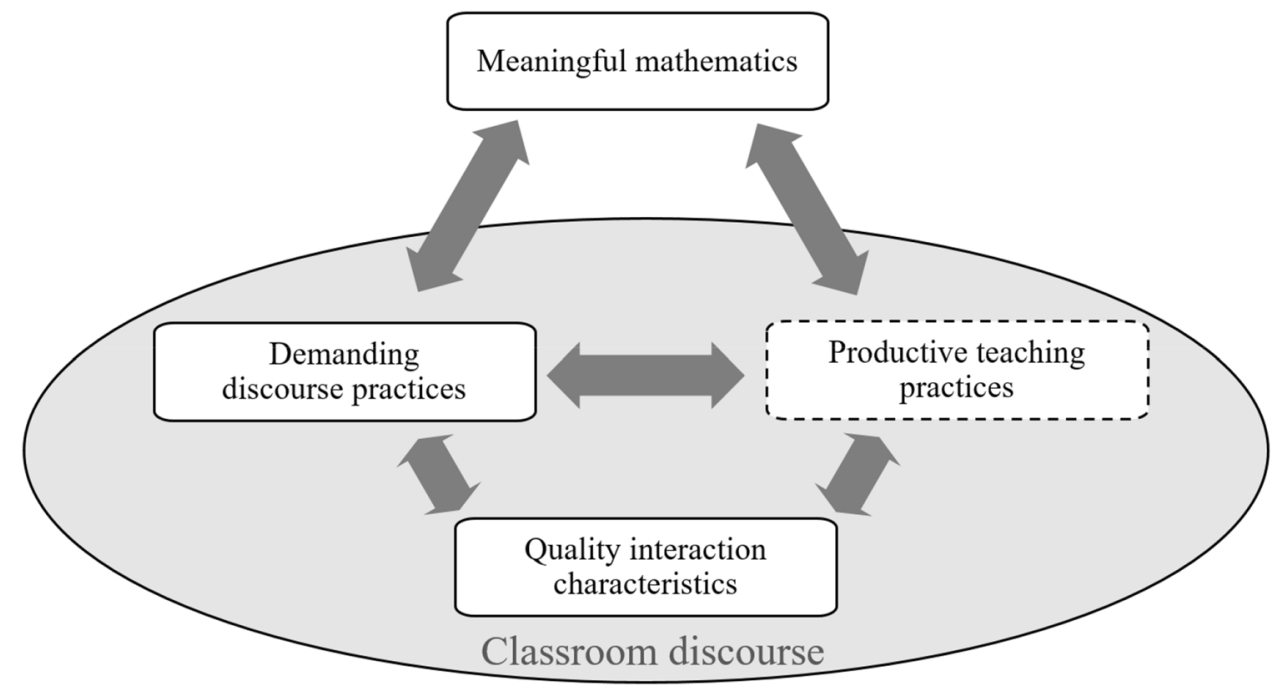

patterns (in line with Barwell, 2020; King, 2008; Mercer et al. 1999; Moschkovich, 2015). Analogically, reporting on procedures and describing visual impressions is aligned with talking about procedural knowledge and early steps of knowledge construction (in line with Setati, 2005). In this context, explaining meanings, arguing, and describing patterns in a general way are subsumed under the term demanding discourse practices as they are demanding from a linguistic perspective and connected to talking about more demanding mathematics and advanced steps in processes of knowledge construction, as linked to learning meaningful mathematics.

In line with Hiebert and Grouws (2007), learning meaningful mathematics is defined as tied to students actively exploring mathematical concepts and discovering their connections. Knowledge of procedures is not reduced to computing and manipulating objects but embedded in conceptual knowledge. Meanings, contexts, and representations play an important role throughout. For mathematical concepts, this understanding of meaningful mathematics is based on genetic approaches (Brousseau, 1997; Freudenthal, 1983) highlighting the importance of doing mathematics and providing students with problems leading them to actively develop a concept for solving the given problem, with the teacher in the role of facilitator and guide. For instance, Brousseau (1997) describes within the framework of the Theory of Didactical Situations (TDS) how learning meaningful mathematics is connected to engaging students in so-called adidactical situations, which are characterized by students' taking on the mathematical responsibility of solving a given problem in groups to facilitate adaptation processes. Learning in adidactical situation depends on carefully designed tasks/problems as well as a considerate teacher accompanying students' learning processes. Typical processes observed with students working in adidactical situations (Brousseau, 1997) include activating previous knowledge and initial, individual ideas, explaining one's thinking, listening, and understanding the other students' approaches. At the end, students need to agree on a solution for the given problem and justify why it works or does not work. That means students successfully working in adidactical situations particularly make use of the DDP explaining and arguing, and engage in characteristics of quality interaction such as helping each other, sharing information, resources, and knowledge, constructively challenging each other's thinking, and jointly making decisions (Sect. 2.2). This alignment of DDP and characteristics of quality interaction are further disentangled theoretically in the following, and empirically in Sect. 5.

Figure 4 shows a collection of main quality interaction characteristics (abbreviated QICs) from research on productive group work (Sect. 2.2). QICs comprise features of student-student interaction that were empirically identified as contributing to productive group work that is shown to be connected to learning gains. More precisely, Fig. 4 brings together ground rules connected to exploratory talk and characteristics of promotive interaction (see Fig. 1) and is completed by insights from the other studies visited in Sect. 2.2: Revisiting characteristics of quality interaction identified across different research projects from the perspective of discourse practices reveals the intertwining between productive group work and DDPs. For example, helping was shown to be consistently positively related to achievement if helping means giving content-related explanations in Webb's (1991) review of quantitative studies. Explaining is also related to sharing knowledge, whereas challenging each other's thinking and in addition jointly making decisions make arguing about the validity of claims necessary. This is in line with King's (2008) list of group activities that were shown to be connected to higher-order thinking: 
Fig. 4 Quality interaction characteristics (in bold those particularly related to demanding discourse practices)

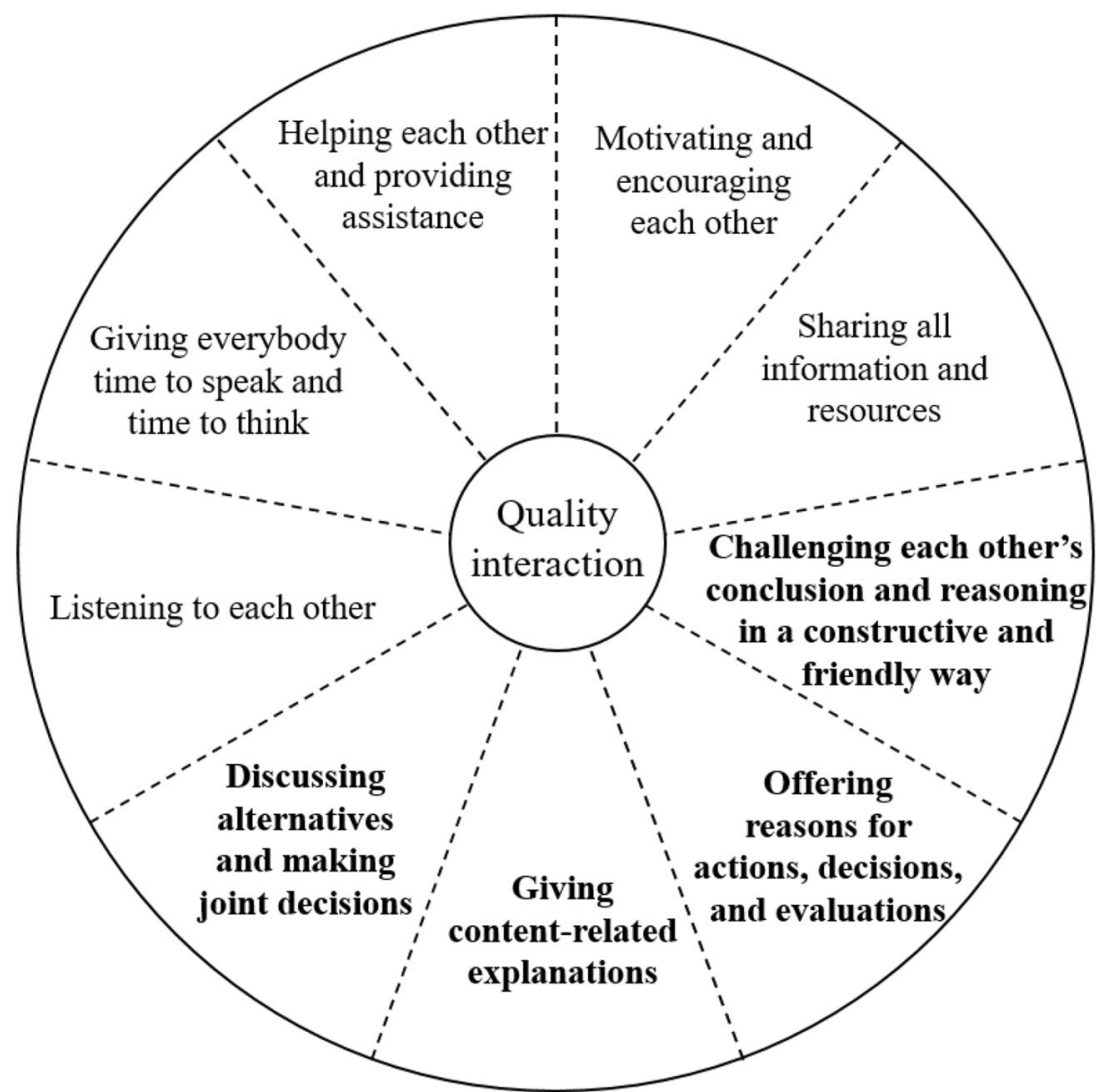

"explaining concepts and processes [...]; asking thoughtprovoking questions [...]; elaborating on content [...]; argumentation [...]; and modeling of cognition" (p. 76). Thus in Fig. 4, QICs that place explaining, arguing, and reasoning in the center of conditions for successful group work are printed in bold to mark that they are connected to DDPs. The non-bold-printed QICs, however, relate to more general characteristics of interaction. For students facing language barriers, engaging in quality interaction intertwined with DDPs might be challenging without further assistance. The aim of the presented study was to investigate the extent to which DDPs and QICs align in student-student interaction and to clarify the extent to which the other students and designed-in scaffolds can offer support.

\section{Research context}

In this section, the research context for investigating how to enhance students' language in group work is presented. In the larger study MAGENTA, the geometrical topic of similarity was chosen, which is part of the grade 9 curriculum in Germany. In Sect. 3.1, mathematical background on similarity is presented, and in Sect. 3.2, the focus task and its underlying design principles.

\subsection{The concept of similarity as learning goal}

The larger study aims at providing a language-responsive learning arrangement (4 lessons of $90 \mathrm{~min}$ ) with a focus on group work for the case of the mathematical concept of similarity. In the first task (see Fig. 5, translated from German by the author), similarity is approached by enlarging figures: one figure is given and another similar figure needs to be found (for a detailed analysis of the mathematical content see Erath 2019, in prep.).

In their previous education, students should have learned about scale in the context of enlarging figures on squared paper (mainly in primary school) and maps as used in geography (mainly in early secondary school). Furthermore, proportionality is part of the curriculum beginning in grade 7 , with a focus on percentages, rule of three, and linear functions. The mathematical learning goal is thus to transfer these acquired arithmetic concepts to the geometrical context and connect them with the idea of preserving shapes, which is fundamental to similarity.

The specific learning goal of the first task in Fig. 5 is to explicitly reject the idea of adding a fixed summand to each side and develop the mathematically sound idea of multiplying each side by a fixed magnification factor. In another paper (Erath 2019, in prep.) I analyze the mathematical 


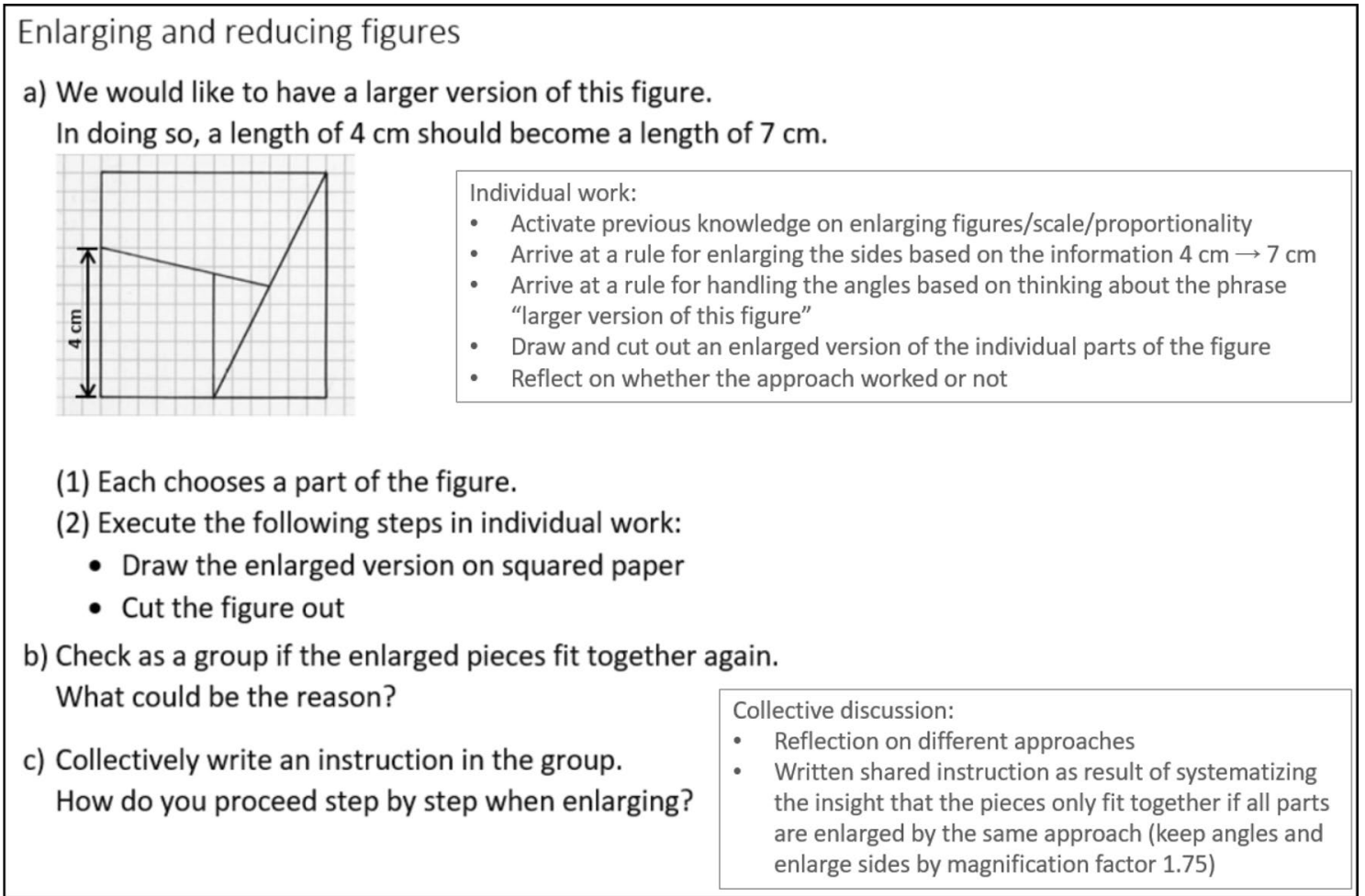

Fig. 5 First task of the learning arrangement on similarity in black, with intendent student action and insights in grey

challenges of this transition in depth, whereas this paper focuses on enhancing students' language.

\subsection{Design principles for the learning arrangement on enlarging figures}

\subsubsection{The task'Enlarging and reducing figures'}

The analysis in this paper is restricted to students working on the task printed in Fig. 5, up to the first systematization of the groups' ideas by writing an instruction as to how to enlarge the figure. It is inspired by Brousseau's Tangram task (1997, p. 177) as it is shown to have the potential to provide rich learning opportunities if embedded in a longer teaching sequence and accompanied by a thoughtful teacher. The aim of MAGENTA is to explore to what extent and how it can be adapted for students facing language barriers in German grade 9 mainstream classrooms. Compared to the context of Brousseau's (1997) study, students in this context are older, already familiar with scale and proportion, and have other language needs. Thus, existing conditions on the Tangram task could not be directly transferred, and some changes to the carefully designed original had to be made. For example, the number of pieces is reduced to one for each student as they are not familiar with the larger Tangram jigsaw. The figure is presented on squared paper as is traditional in the German context, but with fewer measurements indicated, to enable students to start with something with which they are familiar from tasks in geometry so far, namely, recognizing shapes and measuring sides and angles. For the research question in view, the most significant modification concerns the role cards, as is explained in context of design principle DP3.

However, three main ideas were retained, as follows: (1) the aim of eliciting prior knowledge and initial ideas such as adding $3 \mathrm{~cm}$ to each side; (2) if necessary creating a cognitive conflict in the moment of recomposing the enlarged pieces (since the pieces do not form a square if only one piece is not enlarged true to scale); (3) if necessary creating a cognitive conflict in the moment of comparing approaches, recognizing that the length of opposite sides of the enlarged square differ even though all pieces were enlarged by adding $3 \mathrm{~cm}$ to each side (see Sect. 5.2 for an example).

The following design principles elucidate how the learning arrangement was adapted to working with students that might face language barriers.

\subsubsection{DP1: Initiate group work for meaningful collective knowledge construction}

DP1 emphasizes the need to choose a task that really necessitates working in a group (e.g., Cohen, 1994). Furthermore, DP1 highlights that the mathematics to be constructed must be within reach of students' abilities and obtainable by 
means of the resources offered by the task. The theoretical point of reference is genetic approaches (e.g., Freudenthal, 1983) from mathematics education (Sect. 2.3).

The task in Fig. 5 initiates meaningful group work for collective knowledge construction since (1) it is about meaningful mathematics (the concept of similarity to be reinvented), (2) it is designed to create cognitive conflicts if necessary, and (3) there is a real need for accomplishing the task together.

\subsubsection{DP2: Establish language routines for collective knowledge construction}

DP2 is a special case of Erath et al.'s (2021) design principle of establishing a variety of language routines. The design of the task in Fig. 5 implicitly follows the routine think-pair-share. The task starts with a phase of individual work (enlarging a part of the square individually), followed by further working on the results of the individual work in groups of up to four students and-in the case of using the task in regular classrooms-sharing the group's result with the class in a teacher-led discussion. This routine enhances students' language in the following two ways (see Marshman $\&$ Brown, 2014 for a similar routine):

1. The thinking phase allows all students to take their time, work on the task, and prepare for the upcoming discussion with the other group members.

2. The phase of working in groups before sharing with the whole class allows students to work collectively on their ideas and their (verbal) presentation.

\subsubsection{DP3: Enhance quality interaction characteristics and demanding discourse practices}

DP3 is closely linked to design principle (P1) as specified by Erath et al. (2021), and emphasizes that discourse practices need to match the different steps of knowledge construction (Sect. 2.3 and the systematization in Fig. 7). Enhancing DDPs is implemented by a task that enforces group work (see DP1) and makes explaining and arguing almost inevitable.

As argued above, the case of unmoderated group work makes it necessary to think about designed-in scaffolds supporting QICs, which also might lead to enhancing DDPs, as QICs and DDPs are interwoven parts of productive interaction. The central design element for accomplishing this design task are role cards (Fig. 6) assigning different responsibilities, as repeatedly suggested in the literature on supporting quality interaction (Sect. 2.2). The roles were designed to support QICs in general. Broadly, the roles of social manager and communication manager refer to the non-bold-printed QICs in Fig. 4. In addition, systematization manager and process manager addressed the communication in the more advanced steps of knowledge construction and were intended to evoke the bold-printed QICs in Fig. 4 and the related DDPs in particular, by encouraging students to ask for explanations. But the responsibilities of social and communication manager also contribute to supporting DDPs, since challenging each other's ideas in a constructive way or asking for explanations is unlikely to happen if students do not listen to each other or do not treat each other with respect.

Roles were assigned to students and collectively read, discussed, and sometimes complemented before work on the task started. In addition to a short job description, each role card includes examples of statements or questions. Blank speech bubbles for individual additions were included to deepen students' processing and identification with the respective role. In case only three students were present, investigators were advised to omit either social or communication manager as the roles of systematization and process manager resemble the roles of facilitator and recorder from the Complex Instruction approach and were shown to support quality interaction leading to learning gains (Cohen \& Lotan, 1997).

\subsubsection{DP4: Use macro-scaffolding by sequencing and combining learning opportunities}

DP4 is one of the six major design principles systematized by Erath et al. (2021). It purposefully connects ideas of sequencing learning opportunities for learning language and for learning mathematics. The presented study refers to genetic approaches (e.g., Freudenthal, 1983) for talking about mathematical learning opportunities, and makes the discourse practices particularly explicit: language-learning opportunities are sequenced, starting from reporting on procedures and describing visual impressions, and increasing the demand towards explaining and arguing.

The intended sequence of mathematical and languagelearning opportunities is printed in Fig. 7, which relates steps in the process of knowledge construction induced by the task and discourse practices for talking about the respective mathematics. Figure 7 is not intended as an inflexible frame that needs to be followed in a fixed sequence. Rather, it sets out phases that can overlap and between which students flexibly switch while working on the task.

\subsection{Refined research questions}

After introducing theoretical background and research context, the broader question, concerning the extent to which designed-in scaffolds and the other students in the group can support students in overcoming possible language barriers and engaging in quality interaction, can be further specified 


\section{Social manager}

You are responsible for arranging successful collaboration:

1) Motivate all group members to share their ideas and solutions.

2) Make sure that all are listening to each other and everyone can finish speaking.

3) Ask your fellow group members if they understood everything.

Use the following questions:

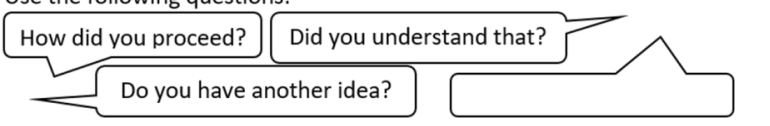

Systematization manager

You are responsible for saving your results:

1) Ask if you have not understood the explanation of a group member.

2) At the end of each discussion, summarize the results orally.

3) Write down your group's results at the end. Always discuss with your group and read aloud what you have written down.

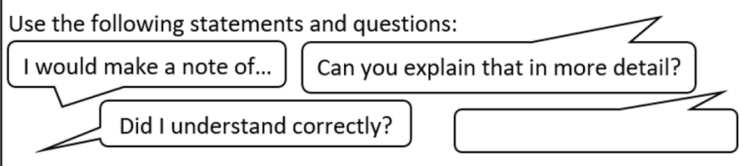

\section{Process manager}

You are responsible for the correct handling of the task:

1) Read the task aloud at the beginning and explain it in your own words. If you do not understand something, ask another group member.

2) Make sure that individual work phases and time limits are respected.

3) At the end of each subtask, check that all questions have been answered.

Use the following statements and questions:

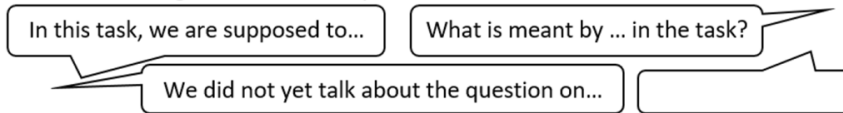

Communication manager

You are responsible for attending to communication:

1) Make sure that you treat each other with respect.

2) Make sure that you do not speak so loudly as to disturb other groups.

3) Have your team formulate a question for you when your group is stuck. You can then go to the teacher (alone) with this question.

Use the following statements and questions:

Let's keep our voices down. What should I ask the teacher? Could you please speak a little louder, we can't hear you otherwise.

Fig. 6 Role cards distributed to the students

\section{Steps of knowledge construction induced by the task}

Discourse practices

for talking about the respective mathematics

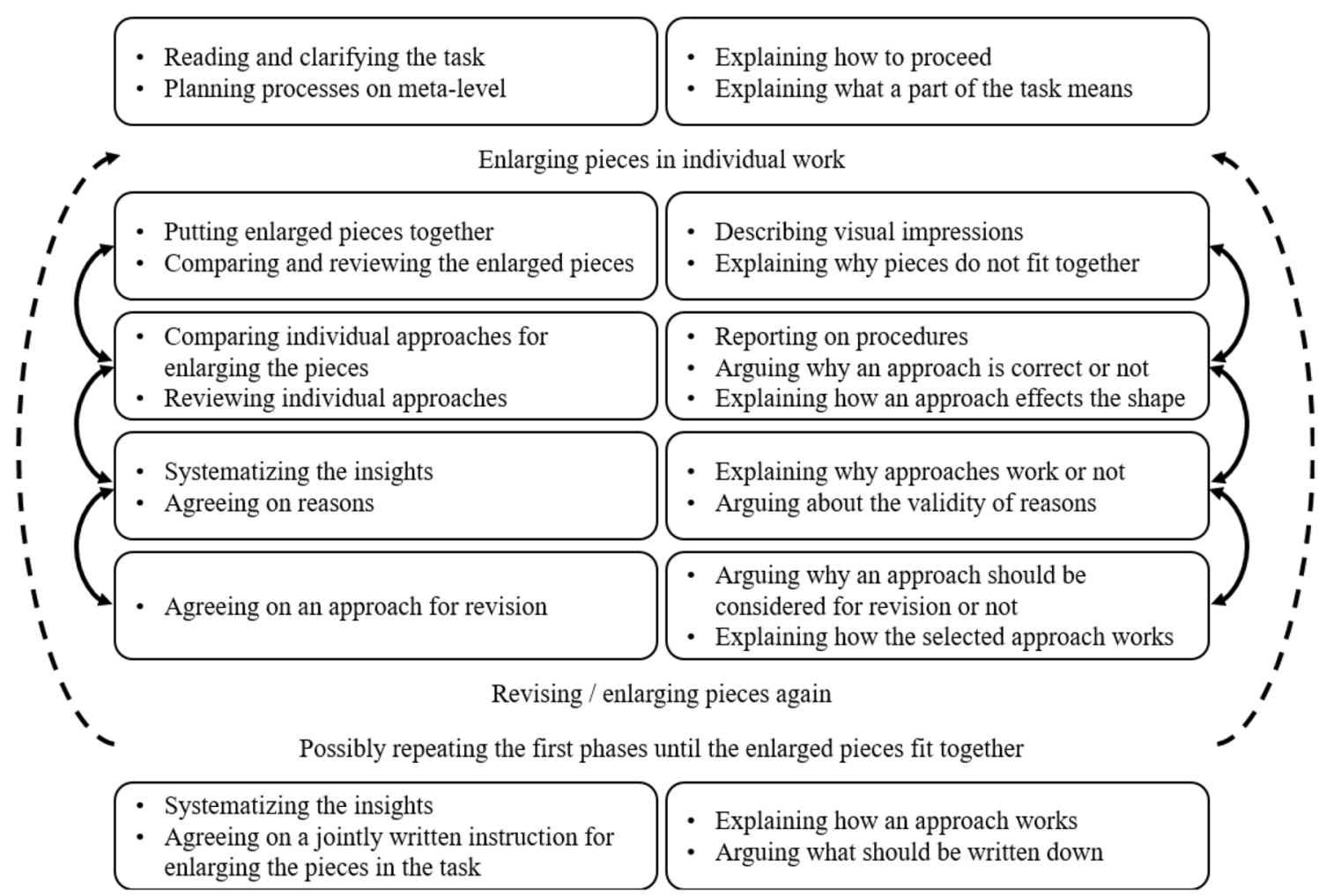

Fig. 7 Steps of knowledge construction and related discourse practices for the task in view 
in the following two research questions. As the conditions of the design experiments (Sect. 4.1; only 3 lessons conducted by pre-service teachers as investigators not familiar with the students) limit the possibilities of establishing norms and explicitly working with students on how to act in group work in advance, particular focus will be given to the design element of assigning roles:

(RQ1) Which QICs and DDPs can be identified in students' speaking concerning enlarging figures in unmoderated group work?

(RQ2) To what extent does the design element 'role cards' enhance QICs and DDPs?

\section{Methodology and methods: Design research with a focus on learning processes}

The research project MAGENTA is being conducted in the methodological framework of Design Research in the learning process perspective (Prediger et al. 2015), more precisely in the FUNKEN model (Fig. 8). On the design level, the project aims at addressing further specified and structured learning content (with similarity as the central concept), refined design principles (especially for enhancing language in group work), and a learning arrangement that can be offered to teachers to use in their regular classrooms. On the research level, the focus is on empirical insights and contributions to local theories on learning and teaching processes connected to students' collective processes of knowledge construction in group work, in the case of similarity.

\subsection{Methods of data collection}

This paper is based on data from the second and, so far, last cycle of design experiments (Fig. 8), in which students (aged 14-16) from secondary schools in an economically underprivileged urban area in Germany with heterogeneous mainstream classrooms (comparable to the students in Prediger et al. 2018) first encountered similarity during 3 lessons. The collective processes of 14 groups (with 2-4 students each) were filmed, and written documents were collected. The design experiments took place in school, but outside regular mathematics lessons.

The design experiments were conducted by 5 pre-service teachers acting as investigators as part of the requirements for their Master's theses. They were introduced to major design principles and their role in several PD sessions. The start of the learning arrangement (Fig. 5) and the role cards (Fig. 6) were provided by the author. The investigators were asked to adapt the later tasks based on the groups' learning processes.

\subsection{Methods of the qualitative data analysis}

The qualitative analysis of the transcribed video data was conducted under four lenses. For each lens, the analysis was conducted separately in the order printed in Fig. 9, which moreover gives an overview of the categories of each lens. In a fifth step, the results of the previous steps were brought

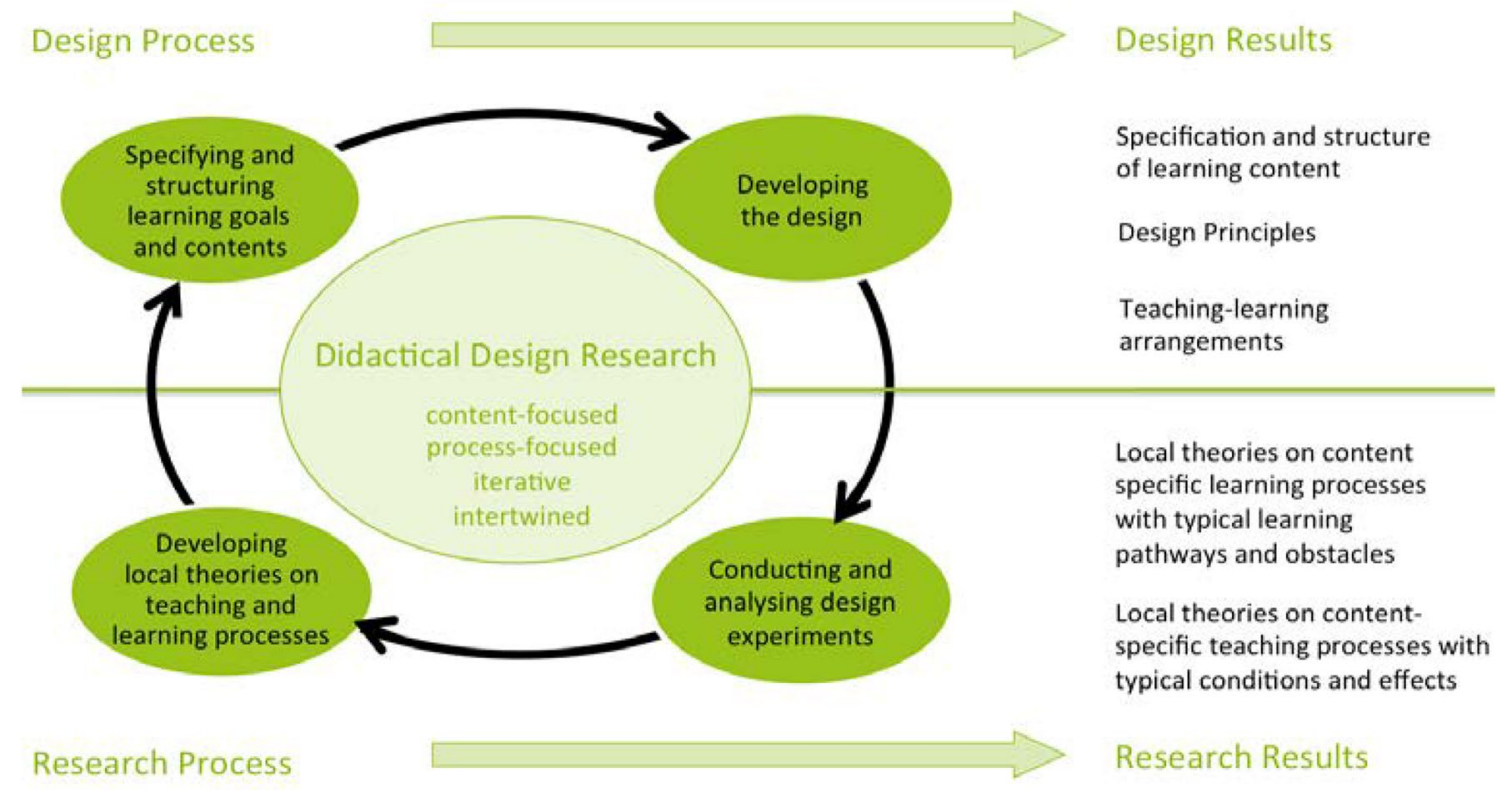

Fig. 8 FUNKEN model for Didactical Design Research (Prediger \& Zwetzschler, 2013) 


\begin{tabular}{|c|c|c|}
\hline \multicolumn{3}{|c|}{ Step 1: Lens on steps of knowledge construction } \\
\hline \multicolumn{2}{|c|}{$\begin{array}{l}\text { Sections of different steps of } \\
\text { knowledge construction were identified } \\
\text { in students' talk referring to the } \\
\text { categories on the left side of Figure } 7 \text {. } \\
\text { Furthermore, students' mathematical } \\
\text { ideas and conclusions were identified } \\
\text { by reconstructing their enlarged pieces } \\
\text { and relating their utterances to their } \\
\text { enlargements. The extract in Section } \\
5.2 \text { is an example for this part of } \\
\text { analyzing with the mathematical lens. }\end{array}$} & $\begin{array}{l}\text { Categories from the left side of Figure } 7: \\
\text { - Reading and clarifying the task } \\
\text { - Planning how to proceed } \\
\text { - Comparing enlarged pieces together } \\
\text { - Comparing and reviewing the enlarged pieces } \\
\text { enlarging the pieces } \\
\text { - Systematizing the insights } \\
\text { - Agreeing on reasons } \\
\text { Agreeing on a jointly written instruction for enlarging } \\
\text { the pieces in the task }\end{array}$ \\
\hline & & \\
\hline \multicolumn{3}{|c|}{ Step 2: Lens on discourse practices } \\
\hline $\begin{array}{l}\text { Discourse practices were } \\
\text { identified in students' talk by } \\
\text { referring to the definitions } \\
\text { offered by IDA and as } \\
\text { adapted to talking about } \\
\text { mathematics (see Section } 2.2 \text { ). } \\
\text { The right side of Figure } 7 \text { lists } \\
\text { the categories that were } \\
\text { specified for the task in view. } \\
\text { The typical mixture of } \\
\text { different practices in students" } \\
\text { talk was considered by } \\
\text { multiple coding. }\end{array}$ & \multicolumn{2}{|c|}{ 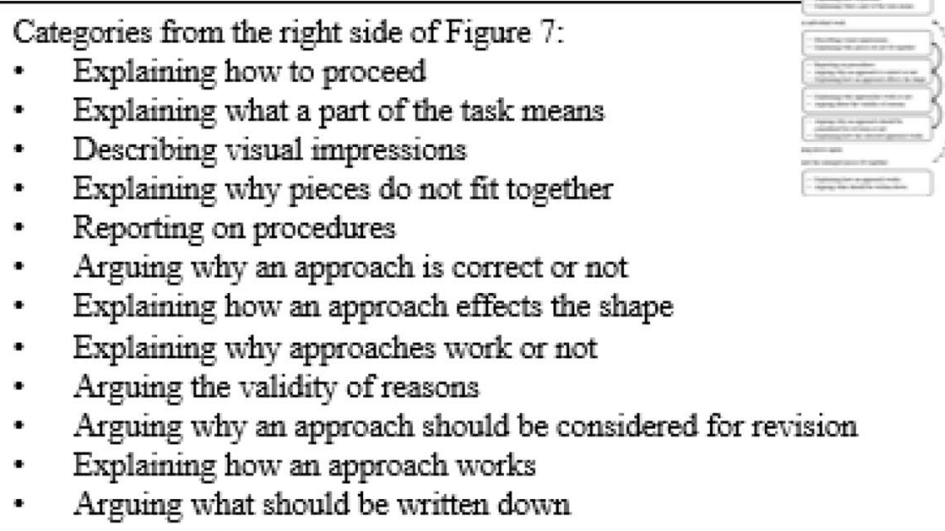 } \\
\hline
\end{tabular}

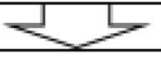

\begin{tabular}{|c|c|}
\hline Lens on & interaction characteristics \\
\hline $\begin{array}{l}\text { Quality interaction characteristics were } \\
\text { identified by referring to the categories } \\
\text { extracted from the literature in Section } 2.3 \\
\text { and summarized in Figure } 4 \text {. Whereas } \\
\text { listening to each other and giving everybody } \\
\text { time to speak and think cant only be observed } \\
\text { indirectly by referring to the length of } \\
\text { pauses, overlapping speech, and if students } \\
\text { look at the speakers, all other categories can } \\
\text { be observed directly by attending to } \\
\text { students' utterances in interaction. }\end{array}$ & $\begin{array}{l}\text { Categories from Figure } 4 \text { : } \\
\text { - Listening to each other } \\
\text { - Giving everybody time to speak and time to think } \\
\text { - Helping each other and providing assistance } \\
\text { - Motivating and encouraging each other } \\
\text { - Sharing all information and resources } \\
\text { - Giving content-related explanations } \\
\text { - Offering reasons for actions, decisions, and } \\
\text { - Cvaluations } \\
\text { - Challenging each other's conclusion and } \\
\text { reasoning in a constructive and friendly way }\end{array}$ \\
\hline
\end{tabular}

\begin{tabular}{|c|c|c|}
\hline & Step 4: Lens on assigned roles & $=$ \\
\hline $\begin{array}{l}\text { The realization of the assigned } \\
\text { roles was observed by } \\
\text { comparing to what extent } \\
\text { students' utterances and } \\
\text { actions match the job } \\
\text { descriptions and } \\
\text { responsibilities of their } \\
\text { assigned roles. }\end{array}$ & $\begin{array}{l}\text { Examples from Figure 6: } \\
\text { - How did you proceed? } \\
\text { Do you have other ideas? (Social manager) } \\
\text { - In this task, we are supposed to... / What is t } \\
\text { task? (Process manager) } \\
\text { - I would make a note of... / Can you explain } \\
\text { (Systematization manager) } \\
\text { - What should I ask the teacher? Let's keep ou } \\
\text { (Communication manager) }\end{array}$ & $\begin{array}{l}\text { meant by ... in the } \\
\text { that in more detail? } \\
\text { ar voices down }\end{array}$ \\
\hline
\end{tabular}

Fig. 9 Overview of the four lenses of analysis and the related categories for analysis 
together and the relationship between the four lenses was investigated as illustrated in Sect. 5. The analysis followed the methodological approach of Interactional Discourse Analysis in line with a participationist perspective from mathematics education (Erath et al. 2018), with the purpose of seeking to grasp and understand particular aspects of interaction and discourse in more detail.

Categories for discourse practices and quality interaction characteristics were attached to transcript sections that were identified as contributing to a step of knowledge construction, because single utterances cannot account for engaging in categories that are rooted in interaction. The categories for Steps 1-3 resonate with the intended steps and task design. They were complemented and refined after a first round of data analysis with related empirical insights, in order to grasp all observable phenomena. Only the lens on the assigned roles more closely focused on single utterances and their embedding in interaction. Here, students' utterances were compared to utterances that would typically match the aims of the assigned responsibilities.

The transcripts in Sect. 5 were translated from German by the author, attempting to preserve students' language use. If necessary for understanding the verbal utterances, further information on gestures etc. as well as pauses longer than two seconds were added in brackets. "\#” indicates turn taking without pause.
Two focus groups were selected for presentation in Sect. 5 for three reasons: (1) They represent the target group, being middle-achieving students facing language barriers (as assessed by teachers' long-term evaluation); (2) they are highly engaged and really try to solve the problem; (3) the investigators intervened very little after handing over the responsibility of the learning process to the students, which allowed the group processes to be observed most easily.

Before handing out the task, the responsibilities associated with the role cards (Fig. 6) were briefly introduced, and it was made explicit that students were supposed to work as a group towards a joint goal and that the investigators would stay in the background, but be there if students asked for help. Figure 10 shows the enlarged versions of the pieces and gives brief information on students' strategies for enlarging their pieces. These strategies were identified by measuring the pieces (if not cut in the later processes), observing students' drawing processes, and connecting them with their utterances and written products. In the following, Dana (systematization manager), Joena (process manager), Phylisha (social manager), and Sarah (communication manager) are referred to as group 1; Hamsa (process manager), Jussuf (systematization manager), and Younis (communication manager) are referred to as group 2.
Fig. 10 Overview of enlarged pieces and strategies

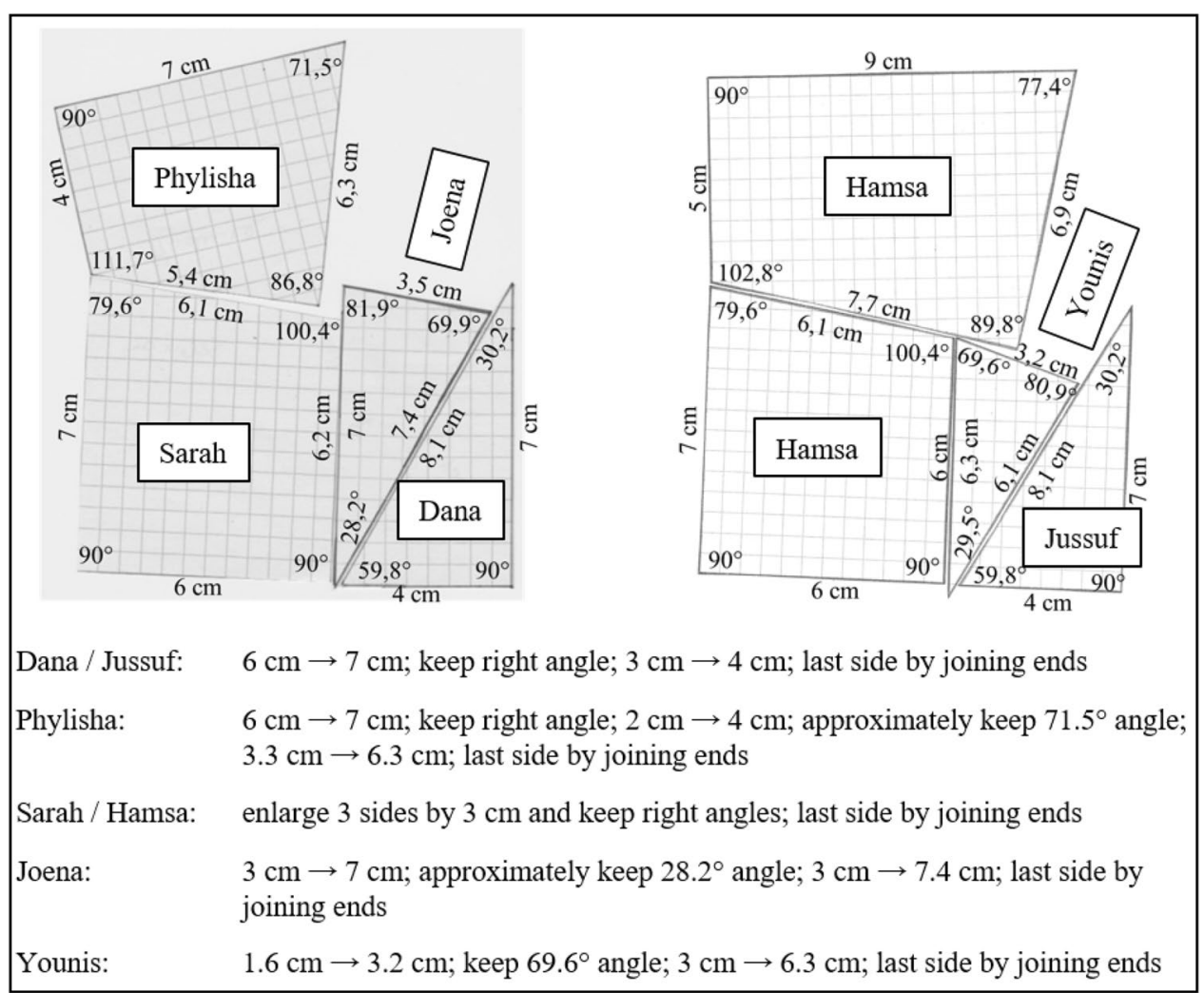




\section{Empirical insights}

Section 5.1 illustrates key insights from the analysis of the whole data set referring to episodes from the advanced step of knowledge construction 'systematizing insights and agreeing on reasons'. Section 5.2 complements these insights with a short episode from the step 'comparing and reviewing approaches for enlarging the pieces' from group 2.

\subsection{Discourse practices, quality interaction characteristics, and roles in an advanced step of knowledge construction}

The two episodes start at the same point in the working process. Both groups put together their enlarged versions of the pieces, made sure they really do not fit and shared their approaches for enlarging and proceeded with 'systematizing insights and agreeing on reasons' as to why the pieces do not fit together, as relates to part (b) of the task.

After presenting the episodes, the following repeatedly observed key insights are illustrated (see also Fig. 11). Both groups work well together, as several QICs can be observed and they arrive at a shared understanding of what to note. Students engage in describing visual impressions, which could serve as a basis for explaining why approaches work or not and arguing about the validity of reasons as adequate for this step of knowledge construction. But they do not continue to link their visual impressions to characteristics of their arithmetic approach resulting in writing down their observations. Whereas utterances related to the process and systematization manager roles can be identified, this is not the case for the other assigned roles.
Quality interaction characteristics:

- Listening to each other

- Giving everybody time to speak and time to think

- Helping each other and providing assistance

- Motivating and encouraging each other

- Sharing all information and resources

- Giving content-related explanations

- Offering reasons for actions, decisions, and evaluations

- Challenging each other's conclusion and reasoning in a constructive and friendly way

- Discussing alternatives and making joint decisions
Repeatedly observed in all steps of knowledge construction

Roles assigned to students:

- Worked well in steps of 'systematizing the insights' and 'planning processes'

Partially observed; particularly 'offering reasons' and 'challenging each other' seem to be missing in advanced steps of knowledge construction
Discourse practices:
- Most often identified (regardless of the step of knowledge construction):

- Describing visual impressions

- Reporting on procedures

- Explaining how

- Demanding discourse practices only in rudimental approaches in advanced steps of knowledge construction

- Failed to support demanding discourse practices and the related quality interaction characteristics in the steps 'comparing and reviewing' enlarged pieces or individual approaches

- Roles of systematization and process manager were observed comparatively more often

Fig. 11 Summary of the key insights from the qualitative analysis 


\subsection{Episode from group 1}

\begin{tabular}{|c|c|c|}
\hline 96 & Joena: & Ok, what are we gonna do? [5 s.] [to the investigator] Shouldn't we do it again then?\# \\
\hline 97 & Phylisha: & \#We should, no, we should write what, why it doesn’t fit together \\
\hline \multicolumn{3}{|l|}{$\ldots$} \\
\hline 100 & Joena: & So the pieces don't fit together. Because\# \\
\hline 101 & Sarah: & \#Cause we didn't do it right \\
\hline 102 & Joena: & We're supposed to give reasons \\
\hline 103 & Sarah: & Yes, I did \\
\hline 104 & Phylisha: & That's because, um \\
\hline 105 & Dana: & Well, we did, so I don't have\# \\
\hline 106 & Phylisha: & \#We should have made this bigger and the other two figures should have been smaller \\
\hline \multicolumn{3}{|l|}{$\ldots$} \\
\hline 112 & Joena: & So two figures should have been bigger and two figures a little bit, a little bit smaller \\
\hline \multicolumn{3}{|l|}{$\ldots$} \\
\hline 116 & Joena: & Could be, yeah, cos we're not, cos maybe if you were bigger, then maybe it would've still fit \\
\hline 117 & Dana: & Yeah, because we didn't, we just didn't enlarge it properly \\
\hline \multicolumn{3}{|l|}{$\cdots$} \\
\hline 120 & Joena: & [Students start taking notes] So should I say that sentence again? \\
\hline 121 & Dana: & $\begin{array}{l}\text { Yeah, so we all have the same one } \\
\text { [all note on their worksheet: "Two figures should have been larger and the other two figures could be a } \\
\text { bit smaller."] }\end{array}$ \\
\hline
\end{tabular}

\subsection{Episode from group 2}

\begin{tabular}{|c|c|c|}
\hline 101 & Hamsa: & Well [unclear] calculate. Well, what should we note for b now? \\
\hline 102 & Jussuf: & Ah, I'm doing that. Um \\
\hline \multicolumn{3}{|l|}{$\cdots$} \\
\hline 108 & Jussuf: & What could be the reason? Tell me. Um [5 s.] \\
\hline 109 & Hamsa: & Maybe because\# \\
\hline 110 & Jussuf: & $\#[$ unclear $] \#$ \\
\hline 111 & Hamsa: & $\begin{array}{l}\text { \#you couldn't make this data the same way it is on this sheet here. Cause look, it goes through like this [points to the } \\
\text { diagonal in the drawing on the worksheet] and you have to do it just as the same way. [ } 5 \mathrm{~s} \text {., Younis and Jussuf laugh] }\end{array}$ \\
\hline 112 & Jussuf: & No idea why that could work. Look, here, here it's\# \\
\hline 113 & Hamsa: & \#Cause it is also that crooked\# \\
\hline 114 & Jussuf: & Yes, yes and here it's also different values, how do you say, scale. Here for example 6 and there we have to $12 \#$ \\
\hline 115 & Hamsa: & \#Yes, write down \\
\hline 116 & Jussuf: & What should I write down? \\
\hline 117 & Hamsa: & Hehe, you were saying! \\
\hline 118 & Jussuf: & Yes, there are different scales \\
\hline \multicolumn{3}{|l|}{$\ldots$} \\
\hline 121 & Hamsa: & And because it's like, thing, crooked, like \\
\hline 122 & Jussuf: & $\begin{array}{l}\text { And because it's crooked } \\
\text { [all note on their worksheet: "Different scales and because it is crooked."] }\end{array}$ \\
\hline
\end{tabular}




\subsubsection{Analysis of quality interaction characteristics}

Several QICs were identified in the presented extracts. For example, the long pause in line 108 following Jussuf's question indicates giving everybody time to speak and time to think. As students in both groups add to each other it can be assumed that they listen to each other.

All students (but Younis who does not speak in the episode) engage in sharing all information and resources and discussing alternatives and making joint decisions as they make their thinking explicit to the group and jointly make the decision what to note.

Both groups thereby engage in offering reasons as indicated at the beginning of the extracts (line 97 Phylisha; lines 100 and 102 Joena; line 108 Jussuf) and their written answers.

\subsubsection{Analysis of discourse practices}

Looking at discourse practices, arguing about the validity of a reason can be observed in lines 100-103 between Joena and Sarah, since Joena implicitly evaluates Sarah's answer as not offering reasons which is rejected by Sarah but not further discussed as Phylisha (line 104) probably interrupts them. The discourse practice arguing about the validity of a reason is adequate for the step of knowledge construction but not mathematically deepened as the group then engages in describing visual impressions by talking about how their enlarged pieces should have looked (lines 106, 112, 116). Dana (line 117) starts to trace the visual impressions back to their (arithmetic) approaches, which is backed up by the others (lines not printed) but again not deepened. Thus the group works out the basis for explaining why approaches do not work but does not continue in this direction and notes the observations without giving proper mathematical reasons for them.

This can be observed similarly in the transcript from group 2. Hamsa, referring to features of the shape (line 111), and Jussuf comparing the length of corresponding sides (line 114), engage in describing visual impressions in even more detail than the students in group 1. But the students in group 2 do not make use of this basis for further investigating the reasons behind their impressions, and thus for instance do not engage in explaining why an approach works or not. Beyond the level of discourse practices, it is notable that both students struggle on the lexical level in their longer utterances and miss the mathematical meaning of scale since they seem to use it synonymously with length.

\subsubsection{Analysis of roles}

Utterances indicating that students act according to their assigned roles can be observed only partially. The process managers Joena (line 96) and Hamsa (line 101) structure the process and initiate the advanced step of knowledge construction in focus in this section, and thus implicitly make QICs and DDPs necessary. Jussuf (as systematization manager, lines $102,108,116,122)$ takes responsibility for noting the reasons the group agrees on, not by writing down his thinking but by asking for the others' input. Dana (line 121) also acts according to her role, as she supports a shared written product. However, the social and communication manager roles cannot be observed explicitly.

\subsubsection{Bringing together the analysis}

In both episodes, QICs focusing on general interaction can be observed, as well as making joint decisions and offering reasons as QICs related to DDPs. However, these reasons do not refer to the mathematically interesting question of why the initial approaches do not work, as they stay on a rather superficial level. The analysis of discourse practices adds to this insight, as students describe visual impressions but do not engage in explaining why approaches work or not. Thus (as theoretically outlined in Sect. 2.3) only partially addressed QICs align with students not engaging in DDPs (indicated by the bidirectional arrow in Fig. 11).

Furthermore, the analysis of QICs provides hints about reasons for the absence of utterances explicitly matching the social and communication manager roles. In both groups, the QIC related to general interaction can be observed, and thus the students managing the roles do not need to explicitly intervene in the interaction. Moreover, all students (at least implicitly) agree with the offered descriptions as valid reasons, so there is no need to challenge each other's thinking and thereby also no need to engage in DDPs. These assumed relationships are indicated by the dashed bi-directional arrows between roles and QICs, as well as between roles and DDPs, in Fig. 11.

\subsection{Interplay of DDPs and the absence of QICs}

The following episode from the step 'comparing and reviewing approaches' complements the insights from Sect. 5.1 from the perspective of QICs and their intertwinement with DDPs.

In the ongoing discussion, Jussuf and Hamsa come across the second designed-in cognitive conflict: Jussuf enlarged the right vertical side of the square by adding $3 \mathrm{~cm}$, resulting in a length of $9 \mathrm{~cm}$. Hamsa enlarged the left vertical side by enlarging two pieces and added $3 \mathrm{~cm}$ each, resulting in a total length of $12 \mathrm{~cm}$ (see right side of Fig. 4): 


\begin{tabular}{|c|c|c|}
\hline 161 & Jussuf: & When you put it on top like that, then it's 9 [puts the piece in front of Hamsa] \\
\hline 162 & Hamsa: & But that's $12 \mathrm{~cm}$ now \\
\hline \multicolumn{3}{|l|}{... } \\
\hline 169 & Hamsa: & $\begin{array}{l}\text { But look, I did this one } 4 \mathrm{~cm} \text { alone and I did this one I did also alone. [points to the left side of the square] Because } 4 \mathrm{~cm} \\
\text { plus 3, that's 7, and then here again } 2 \text { plus 3, that's 5. Don't you get it? }\end{array}$ \\
\hline 170 & Jussuf: & Sure, I get it. But you have to do all- You don't always have to everything together [4 s.] \\
\hline \multicolumn{3}{|l|}{$\ldots$} \\
\hline 173 & Hamsa: & $\begin{array}{l}\text { And you know what else was a problem? We did them all one by one. Everybody got a piece, a piece, a piece. Then every- } \\
\text { body has something different in their head and then\# }\end{array}$ \\
\hline 174 & Younis: & Mhm [approving]. That's what I just said \\
\hline
\end{tabular}

From the perspective of discourse practices, the extract offers another example of the key insight from Sect. 5.1. Hamsa and Jussuf state results (lines 161, 162) and engage in reporting on procedures (line 169), which is one of the discourse practices for talking adequately about the mathematics at stake. However, they do not use this as a basis to solve the conflict by means of engaging in the DDP arguing why an approach is correct or not or explaining how an approach affects the shape. The QICs that cannot be observed complete this picture: in particular, challenging each other's conclusions and reasoning and discussing alternatives, are missing. Even though they report their approach for enlarging (Hamsa, line 169) and question the effects of the division of labor (Hamsa, line 173), none of the students question the approach of adding $3 \mathrm{~cm}$ to each side or ask for reasons why it might be a problem that 'everybody got a piece' (Hamsa, line 173). Thus, not engaging in the two mentioned QICs aligns with not addressing DDPs necessary for solving the cognitive conflict.

In addition, no utterance specifically refers to the assigned roles. Thus, in this extract from 'comparing and reviewing approaches' students might not feel the need to act according to their responsibilities as they might be fine with the process. For example, Younis (as communication manager) does not suggest formulating a question that he could pose the investigator to help solve the conflict, as he seems to agree with Hamsa that the problem is not based on their mathematical approach.

\section{Discussion and outlook}

So far, research on productive group work identified quality interaction characteristics (QICs), showed their importance for learning cognitively demanding content such as meaningful mathematics, and developed supports such as role cards to scaffold student-student interaction. Particular supports for students facing language barriers were mostly not in focus. Demanding discourse practices (DDPs) were only implicitly considered as none of the visited studies (Cohen \& Lotan, 1997; Johnson \& Johnson, 2008; King, 2008; Lotan, 2008; Mercer \& Sams, 2006;
Mercer et al. 1999; Webb, 1991) explicitly discussed linguistic demands in students' talk.

DDPs, on the other hand, were mainly considered in teacher-led classroom discourses in mathematics education research (Erath et al. 2018). Hence, the question is still open as to how to support students facing language barriers in group work discussions on meaningful mathematics in advanced steps of knowledge construction. The presented research offers the first step of the empirical work that needs to be done to adapt the design principles from teacher-led settings to group work phases, including identifying and understanding in more detail which language barriers students face and which scaffolds help them in overcoming these barriers.

But, as the discussion of the presented study theoretically and empirically elucidates, there is an intertwinement between several QICs and DDPs. More precisely, a bridge between research on productive group work and research from a participationist perspective in mathematics education with a focus on language learning can be built. It is fascinating that three disparate studies, with a psychology background (King, 2008), with a discourse analysis background (Erath et al. 2018), and with a sociocultural background in mathematics education (e.g., Moschkovich, 2015), highlight similar characteristics of student-student interaction as important for students' learning, and all point to DDPs. Thus, it is beneficial for current and future research to further investigate the intertwinement of QICs and DDPs with the aim of designing supports for students facing language barriers. In this paper, the idea of supporting quality interaction with a focus on DDPs by means of role cards was further explored.

The answer to RQ1 on the identification of quality interaction characteristics and discourse practices is split: whereas QICs of general interaction could be observed in nearly all groups, the ones related to DDPs were only partly observed. Students repeatedly engaged in describing visual impressions and reporting on procedures, but rarely engaged in more elaborate discourse practices like arguing or explaining that would be needed for productive work in later steps of the knowledge construction process. The rare engagement in DDPs is intertwined with the absence 
of the QICs challenging each other's conclusions and reasoning and discussing alternatives. Thus, the task design succeeds in enhancing different discourse practices and engaging students in interaction. But-analogous to observation in whole-class discussions (Erath et al. 2018)-it has to be noted that the focus groups, as well as other groups, repeatedly struggled in engaging in DDPs that would be important for grasping the core issues, in the process of adapting the initial additive ideas towards the mathematically sound multiplicative idea.

The limitations in discourse practices and the absence of the intertwined QICs might be traced back to language barriers in these moments: the observed students try to reason, argue, and give explanations but are limited to expressing their thoughts by describing and reporting on procedures or explaining how. It remains unclear what would have happened if students had engaged in the QICs challenging each other's conclusions and reasoning and discussing alternatives, which might have involved the DDPs explaining or arguing the mathematical conflicts they faced more deeply; it is conceivable, however, that the chances of questioning the additive ideas might have been greater in this case. However, other reasons related to the task design and the teacher-student relationship not focused on in the presented analysis could also explain the limited occurrence of DDPs and related QICs. For example, the method of data collection constrained the possibilities of establishing norms. Furthermore, the changes made to the original Tangram task (Brousseau, 1997) might have reduced its likelihood of leading students to engage in DDPs, and not only to uncover but also to solve the designed-in cognitive conflicts.

Altogether, the presented study refines the long-standing call for enhancing quality interaction in group work (Sect. 2.2) for students facing language barriers. These students need additional support on the language level beyond encouraging QICs in general, to facilitate their engaging in DDPs, and thus support their talking about meaningful mathematics.

Cohen and Lotan (1997) suggest adapting students' assigned roles to their needs. This suggestion was seized on and investigated in the presented study. The design element of different roles assigned to students (RQ2) is promising but seems only functional in certain steps of knowledge construction. It works well during 'planning' and 'systematizing'; in these steps, students work productively as a group and initiate DDPs and related QICs. In particular, the systematization and process manager roles initiate the intended processes (in line with findings by Cohen \& Lotan, 1997). But further elements need to be designed that specifically focus on 'comparing and reviewing' as well as 'agreeing on reasons', since these steps of knowledge construction are not yet sufficiently supported by the implemented roles. Revisiting QICs from the perspective of DDPs further explains why quality interaction is sometimes only barely achieved in these demanding steps of knowledge construction. It might be the case that students in principle follow established ground rules and are aware of characteristics of promotive interaction; however, they might need support on a language level in order to fulfill these characteristics of quality interaction.

Some responsibilities of the social and communication manager were not required. For example, the presented groups, like most others, succeeded in listening to each other and giving each other time to think without intervention from the communication manager. Therefore, one first idea for improving the designed-in scaffolds is to replace the role of communication manager with that of an explaining/ reasoning manager, to encourage the respective QICs asking for reasons and constructively challenging each other's claims as being integral in the ground rules connected to exploratory talk (Barnes \& Todd, 1977; Mercer et al. 1999). However, one challenge might be that the observed students mostly agreed in their thinking (as illustrated in Sect. 5.1) and thus the students responsible for challenging each other's thinking might not have felt the need to intervene.

Going back to the overarching question of the extent to which designed-in scaffolds and the other students in the group can support students in overcoming possible language barriers, the answer is that much more effort must be put into designing elements for explicitly scaffolding DDPs and the related QICs. Unquestionably, a responsive teacher would have been able to take on the students' important mathematical insights, make them accessible to the other students, and guide them to develop a mathematically sound idea, in addition to facilitating students' explaining and arguing. However, the answer cannot be to deny students facing language barriers the (mathematical) learning opportunities arising from group work. Accordingly, instead of arguing for less group work, the presented study calls for further research on how to make these learning opportunities accessible to all students.

Acknowledgements The research project "MAGENTA - Explaining mathematics, discovering geometry, and participating in small group processes. Design research study on supporting mathematical explanations of language learners in grade 9" is funded by the Deutsche Telekom Stiftung (Senior Fellowship Fachdidaktik MINT, Grant no. 0300539 to K. Erath).

Funding Open Access funding enabled and organized by Projekt DEAL.

Open Access This article is licensed under a Creative Commons Attribution 4.0 International License, which permits use, sharing, adaptation, distribution and reproduction in any medium or format, as long as you give appropriate credit to the original author(s) and the source, provide a link to the Creative Commons licence, and indicate if changes were made. The images or other third party material in this article are included in the article's Creative Commons licence, unless indicated 
otherwise in a credit line to the material. If material is not included in the article's Creative Commons licence and your intended use is not permitted by statutory regulation or exceeds the permitted use, you will need to obtain permission directly from the copyright holder. To view a copy of this licence, visit http://creativecommons.org/licenses/by/4.0/.

\section{References}

Barnes, D., \& Todd, F. (1977). Communication and learning in small groups. Routledge \& Keagan Paul.

Barwell, R. (2014). Language background in mathematics education. In S. Lerman (Ed.), Encyclopedia of mathematics education (pp. 331-336). Springer.

Barwell, R. (2020). Learning mathematics in a second language: Language positive and language neutral classrooms. Journal for Research in Mathematics Education, 51(2), 150-178.

Barwell, R., Clarkson, P., Halai, A., Kazima, M., Moschkovich, J., Planas, N., et al. (Eds.). (2016). Mathematics education and language diversity. The 21 st ICMI study. Springer.

Brousseau, G. (1997). The theory of didactical situations in mathematics. Kluwer Academic Publishers.

Cohen, E. G. (1994). Restructuring the classroom. Conditions for productive small groups. Review of Educational Research, 64(1), $1-35$.

Cohen, E. G., \& Lotan, R. A. (Eds.). (1997). Working for equity in heterogeneous classrooms. Sociological theory in practice. Teachers College Press.

Erath, K. (2020). Specifying and structuring the mathematical learning goal similarity. Insights from a design research study in grade 9 . Manuscript inpreparation.

Erath, K., Ingram, J., Moschkovich, J., \& Prediger, S. (2021). Designing and enacting instruction that enhances language in mathematics classrooms. A review of the state of the art. ZDM-Mathematics Education, 53(2), 1-18.

Erath, K., Prediger, S., Quasthoff, U., \& Heller, V. (2018). Discourse competence as important part of academic language proficiency in mathematics classrooms: The case of explaining to learn and learning to explain. Educational Studies in Mathematics, 99, 161-179.

Freudenthal, H. (1983). Didactical phenomenology of mathematical structures. Kluwer.

Hiebert, J., \& Grouws, D. A. (2007). The effects of classroom mathematics teaching on students' learning. In F. K. Lester (Ed.), Second handbook of research on mathematics teaching and learning (pp. 371-404). Information Age.

Johnson, D. W., \& Johnson, R. T. (2008). Social interdependence theory and cooperative learning: The teacher's role. The teacher's role in implementing cooperative learning in the classroom (pp. 9-37). Springer.

King, A. (2008). Structuring peer interaction to promote higher-order thinking and complex learning in cooperating groups. In R. M. Gillies, A. Ashman, \& J. Terwel (Eds.), The teacher's role in implementing cooperative learning in the classroom (pp. 73-91). Springer.

Krummheuer, G. (2011). Representation of the notion "learning-as-participation" in everyday situations of mathematics classes. $Z D M$ The International Journal on Mathematics Education, 43, 81-90.
Lotan, R. A. (2008). Developing language and mastering content in heterogeneous classrooms. The teacher's role in implementing cooperative learning in the classroom (pp. 184-200). Springer.

Marshman, M., \& Brown, R. (2014). Coming to know and do mathematics with disengaged students. Mathematics Teacher Education \& Development, 16(2), 71-88.

Mercer, N., \& Sams, C. (2006). Teaching children how to use language to solve math problems. Language and Education, 20(6), 507-528.

Mercer, N., Wegerif, R., \& Dawes, L. (1999). Children's talk and the development of reasoning in the classroom. British Educational Research Journal, 25(1), 95-111.

Moschkovich, J. (2015). Academic literacy in mathematics for English Learners. Journal of Mathematical Behavior, 40(A), 43-62.

Prediger, S., Erath, K., \& Moser Opitz, E. (2019). The language dimension of mathematical difficulties. In A. Fritz, V. Haase, \& P. Räsänen (Eds.), International handbook of mathematical learning difficulties. From the laboratory to the classroom (pp. 437-455). Springer.

Prediger, S., Gravemeijer, K., \& Confrey, J. (2015). Design research with a focus on learning processes. An overview on achievements and challenges. ZDM-Mathematics Education, 47(7), 877-891.

Prediger, S., Wilhelm, N., Büchter, A., Gürsoy, E., \& Benholz, C. (2018). Language proficiency and mathematics achievementEmpirical study of language-induced obstacles in a high stakes test, the central exam ZP10. Journal für Mathematik-Didaktik, 39(Supp. 1), 1-26.

Prediger, S., \& Zindel, C. (2017). School academic language demands for understanding functional relationships. A design research project on the role of language in reading and learning. Eurasia Journal of Mathematics, Science \& Technology Education, 13(7b), 4157-4188.

Prediger, S., \& Zwetzschler, L. (2013). Topic-specific design research with a focus on learning processes: The case of understanding algebraic equivalence in grade 8 . In T. Plomp \& N. M. Nievven (Eds.), Educational design research. Illustrative cases (pp. 407424). SLO, Netherlands Institute for Curriculum Development.

Setati, M. (2005). Teaching mathematics in a primary multilingual classroom. Journal for Research in Mathematics Education, $36(5), 447-466$.

Sfard, A. (2008). Thinking as communicating. Human development, the growth of discourse, and mathematizing. University Press.

Vygotsky, L. S. (1978). Mind in society: The development of higher psychological processes. Harvard University Press.

Walshaw, M., \& Anthony, G. (2008). The teacher's role in classroom discourse. A review of recent research into mathematics classrooms. Review of Educational Research, 78(3), 516-551.

Webb, N. M. (1991). Task-related verbal interaction and mathematics learning in small groups. Journal for Research in Mathematics Education, 22(5), 366-389.

youcubed. (n.d.). Group Roles. https://bhi61nm2cr3mkdgk1dtaov18wpengine.netdna-ssl.com/wp-content/uploads/2017/03/GroupRoles-Am-Version.pdf. Accessed 5 Aug 2020.

Publisher's Note Springer Nature remains neutral with regard to jurisdictional claims in published maps and institutional affiliations. 